\title{
Investigation of Shear Wave Velocity and Predominant Period Properties of Bornova Plain (IZMIR) and Its Surroundings
}

\author{
Eren Pamuk ${ }^{1}$, Özkan C. Özdağ ${ }^{2}$,Aykut Tunçel ${ }^{1}$ andMustafa Akgün ${ }^{1}$ \\ ${ }^{I}$ Dokuz Eylül University, Engineering Faculty, Department of Geophysical Engineering, Izmir, TURKEY. \\ ${ }^{2}$ Dokuz Eylül University, Aegean Implementation and Research Center, İzmir, TURKEY.
}

\begin{abstract}
We used surface wave methods which includes single-station microtremor methods,Multichannel Analysis of Surface Waves (MASW), Refraction Microtremor(ReMi) for determining the shear wave velocity structure, which is important input parameter of ground and soil type definition in geotechnical earthquake analysis, and predominant period features of Bornova Plain (İzmir) and its surroundings in İzmir, Turkey. Engineering bedrock $(V s>760 \mathrm{~m} / \mathrm{s})$ depths are obtained in north and south parts of thestudy area. When compared, Vs values, predominant periods and geology are generally compatible.
\end{abstract}

Keywords: Shear Wave Velocity; Predominant Period; Bornova Plain, Izmir

\section{Introduction}

In defining earthquake-soil common behaviour, soil-bedrock models areused as a base. In these descriptions, S-wave velocity is (Vs) used as a base. The layers are called soil where the Vs is $<760 \mathrm{~m} / \mathrm{s}$, the bigger ones are called bedrock as well [1].Surface waves methods can be used for Vs-depth profiles. Surface waves can be classified into two groups; active source (e.g., MASW) and passive source (e.g., ReMi and spatial autocorrelationmethod(SPAC)). Vs and thickness values are the basic parameters to create the soil-bedrock models. Various geophysical methods (MASW, ReMi, SPAC etc.) are used for obtaining these parameters. The methods have been used by numerous researchers $[2,3,4,5,1,13,14,15]$.

The aim of this study was to determine soil characterizations that indicate shallow shear wave velocity structure and predominant period featuresin Bornova Plain and its surroundings, an area of İzmir (Figure 1). We utilized both active and passive surface wave methods for this purpose. The level cross sectionswere created up to 50 musing Vs values. The soil thickness and predominant periodare more than $30 \mathrm{~m}$ and $1 \mathrm{sec}$, respectivelyespecially close by the bay.Soilthickness and predominant period decrease towards northand south part of thestudy area.The pre-Neogene Bornova Complex, the Neogene andesiteand limestoneshow engineering bedrock properties inthe north and south part of the study area.

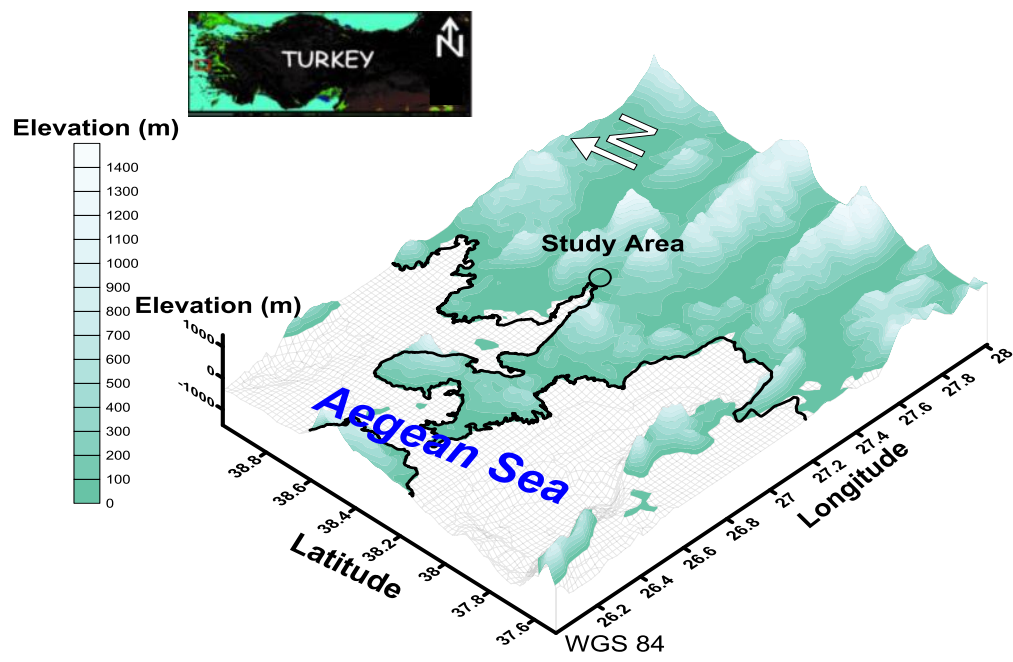

Figure1. Location map of study area.

\section{Geology Of Study Area And Its Surrounding}

Bornova melange is in the oldest geological unit position in the study area. Neogene aged sedimentary rocks come on to Bornova melange as unconformity. These sedimentary rocks are; pebbles, argillaceous limestones and silicified limestone. Volcanite cover theNeogene sedimentary rocks as unconformity [6,1].According to geological studies, Miocene andesite and its derivatives are located to the north of study area and Neogene age limestones to the south of study area.The middle parts of the study area are the Quaternary 
alluvial delta deposits (Figure 2).

\section{Geophysical Methods}

The geophysical site characterization was utilized in the Bornova Plain and its surroundings. MASW,ReMiand single station microtremor (21 sites) measurements were carried out in the study area (Figure2).

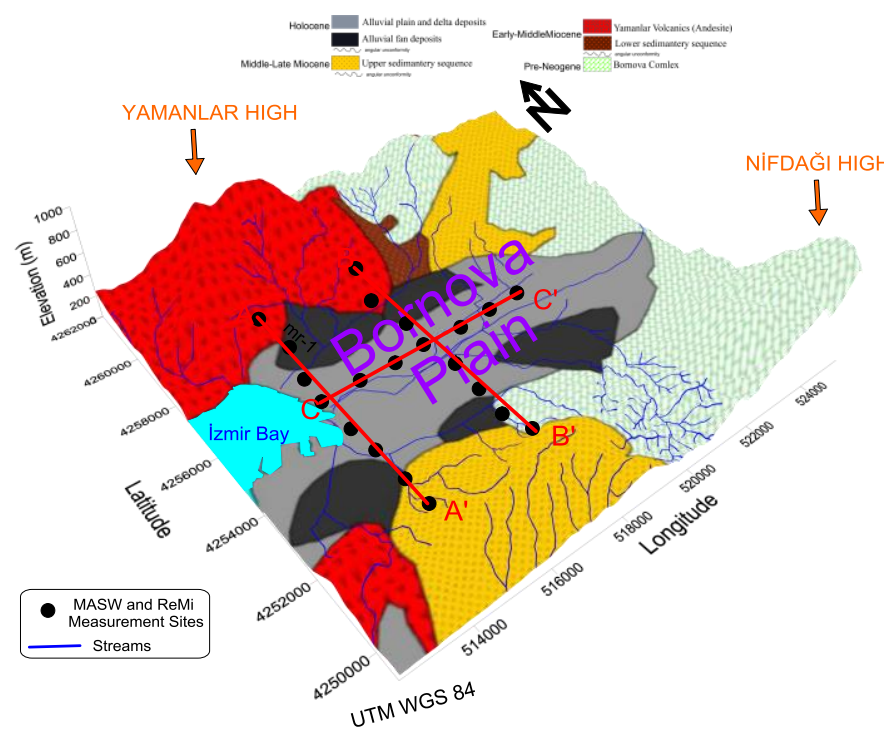

Figure2. Location of MASW and ReMi measurement siteswith geology map of thestudy area (geology map[modified from 7, 8]).

\subsection{MASW and ReMi methods}

MASW, which is active surface wave method, and ReMi, which is passive surface wave method,aremethods of estimating the shear-wave velocity profile from surface waves. They use the dispersive properties of Rayleigh waves for imaging the subsurface layers[9, 10]. In MASW method, surface waves can be easily generated by an impact source (sledgehammer etc.) [9].ReMi has widely been used to determine shear wave velocity profiles using ambient noise recordings. This array analysis technique finds average surface-wave velocity over the length of a refraction array[10]. Table 1 shows that used surface wave methods parameters for this study.

The MASW data processing contains three step basically. The first step is thepreparation of a multichannel record, the second step is dispersion-curve analysis and the last step is to obtain the Vs-depth cross section using the inversion (the least-squares approach etc.). In addition, ReMi measurements were carried out at the same locations where the MASW measurements conducted. The ReMi data processing consisted of three steps like MASW data analysis; 1)Velocity spectral (p-f) analysis. 2) Rayleigh phase-velocity dispersion picking, 3)Shear wave velocity modeling [10]. In this study, Vs-depth cross sectionswere obtained from combined dispersion of ReMi and MASW.

Table 1. Used Surface Wave Methods Parameters for This Study.

\begin{tabular}{|l|l|l|}
\hline & MASW & ReMi \\
\hline Recording channels & 24 & 24 \\
\hline Geophone type & Vertical 4.5-Hz & Vertical 4.5-Hz \\
\hline Source type & $45 \mathrm{~kg}$ sledgehammer & - \\
\hline Geophone interval & $5 \mathrm{~m}$ & $5 \mathrm{~m}$ \\
\hline Offset & 5,10 and $15 \mathrm{~m}$ & - \\
\hline Number of stacks & 3 & 10 \\
\hline Sampling rate & $0.5 \mathrm{~ms}$ & $2 \mathrm{~ms}$ \\
\hline Record length & $1 \mathrm{~s}$ & $30 \mathrm{~s}$ \\
\hline Recording system & Geode & Geode \\
\hline
\end{tabular}

Combined dispersion curves were used in the study in order to increase the depth of the research and to identify the velocity differences that occur within the soil in detail (Figure 3). According to Vs -depth sections obtained from each measurement site, sudden velocity differences were observed in a lateral and vertical direction within the soil (Figure 4). These changes need to be considered for soil dynamic analysis studies. 
Based on the Vs distributions at different depths are made for soil type identification.It has been observed that Vs values changefrom 100 to $1500 \mathrm{~m} / \mathrm{s}$ in A-A', B-B' and C-C' cross sections.
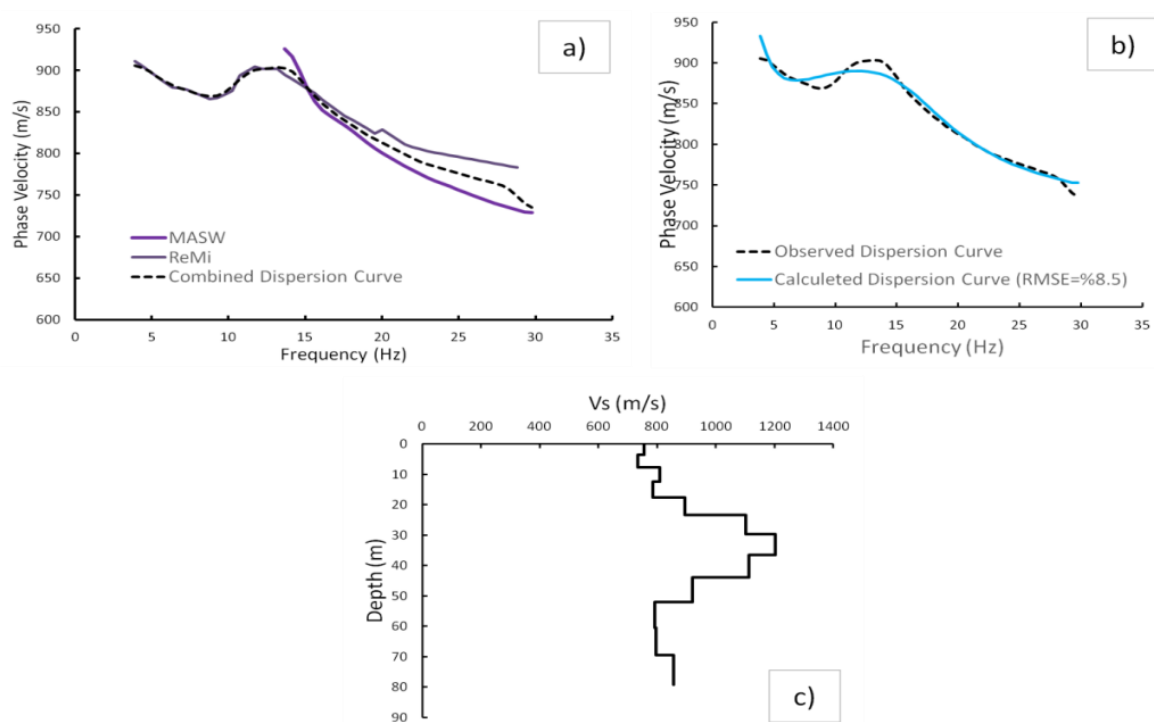

Figure3. Vs-depth cross sectionwere obtained by inverting the combined dispersion curve at MR1 site.

\subsection{Single station microtremor method}

Nakamura's method is based on a theory developed by Nakamura (1989), who demonstrated that the ratio between the horizontal and vertical ambient noise records related to the fundamental frequency of the soil beneath a site. Microtremor observations were carried out at 21 sites in the study area. We used Guralp Systems CMG-6TD seismometer in microtremormeasurements. The recording duration was 30 minutes with a sampling rate of $100 \mathrm{~Hz}$ at each location. To remove intensive artificial disturbance in data processing, all signals were filtered in a band-pass of $0.05-20 \mathrm{~Hz}$. Then they were divided into 80 -second windows and tapered individually using the Konno-Ohmachi smoothing method. For each window, the amplitude spectra of the three components were computed using a Fast Fourier Transform (FFT) algorithm. As a result, the average spectral ratio of horizontal-to-vertical noise components was thus calculated.

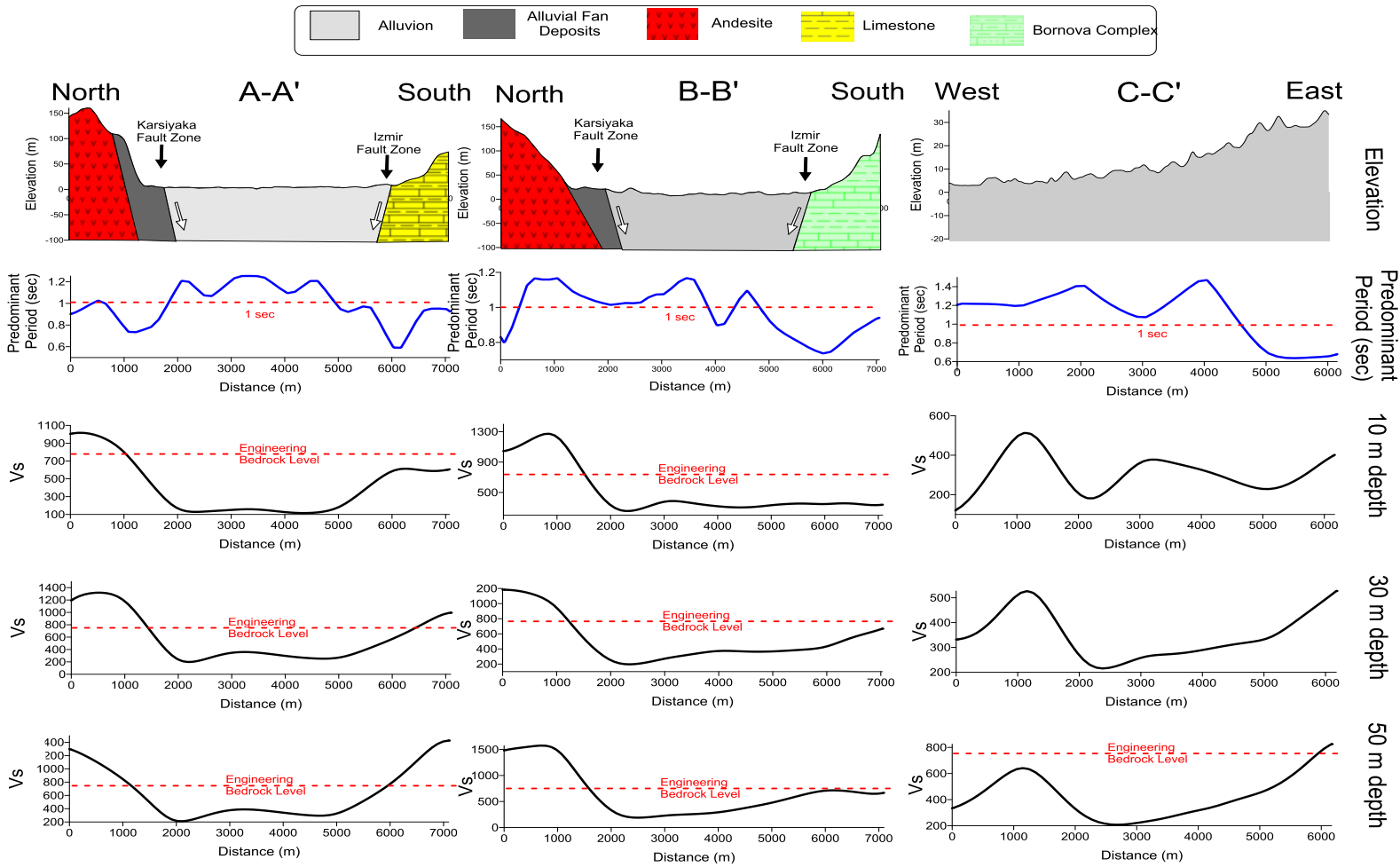

Figure4. Average Vs distribution for different depths and predominant periods of Bornova plain and its 


$$
\text { surroundings }
$$

\section{Conclusion}

When these velocity changes and the geological structure of the area are considered together, andesite's and Miocene pyroclasticin the north of the study area and Miocene aged limestone and pre-Neogene aged Bornova Complexin the south of study areawere observed to have higher Vs values compared to the rest of the study area. The threshold value of bedrock's Vs values is also observed higher than $760 \mathrm{~m} / \mathrm{s}$. In spite of this, Vs values change between 100 and $300 \mathrm{~m} / \mathrm{sespecially} \mathrm{in} \mathrm{the} \mathrm{areas} \mathrm{nearby} \mathrm{the} \mathrm{sea} \mathrm{and} \mathrm{Vs} \mathrm{values} \mathrm{along} \mathrm{the} \mathrm{Bornova}$ plain are lower than $500 \mathrm{~m} / \mathrm{s}$. The predominant period in the range of $0.6-1.4 \mathrm{sec}$, which indicates that the area exhibits lower predominant periods and less soil thickness(Figure4).

In north and south part of the study area,decreasing in predominant period values remarked by the reason of increasing topography and finding a different geological units. The period values are observed to be higher than $1 \mathrm{sec}$ and Vs values are observed to be much lower than $500 \mathrm{~m} / \mathrm{s}$, especially in Quaternary aged and mostly consist of soil layers that are thicker than $30 \mathrm{~m}$.

The Vs distribution profiles were obtained at five different depths, $10 \mathrm{~m}, 20 \mathrm{~m}, 30 \mathrm{~m}, 40 \mathrm{~m}$ and $50 \mathrm{~m}$, respectively for determining the average shear wave velocity distribution with depth. When examining the Vs distribution whichis created up to $50 \mathrm{~m}$ velocity values from $10 \mathrm{~m}$ to $50 \mathrm{~m}$ at the Bornova plain in general are observed to be below $500 \mathrm{~m} / \mathrm{s}$. Due to the relative increase in velocity when going to theeast away from the sea, a decrease in the soil thickness is observed. Vs values at the north and south of the bay are observed to be higher than $760 \mathrm{~m} / \mathrm{s}$. In addition, Vs values suddenly change in lateral and vertical directions between the depths of 10 $\mathrm{m}$ and $50 \mathrm{~m}$. Therefore, it is necessary to make in-situ geophysical measurements along the study area to obtain the dynamic parameters. In addition, we suggest creating the 2D and 3D soil-bedrock models to produce more valuable results.

\section{Acknowledgment}

The authors thank DokuzEylülUniversity, Scientific Research Project Funding (DEU BAP) for their financial support [Project number: 2015KBFEN032].

\section{References}

[1]. E. Pamuk, M. Akgün, Ö. C.Özdă̆,T.Gönenç., 2017. 2D Soil and Engineering-Seismic Bedrock Modeling of Eastern Part of İzmir Inner Bay/Turkey, Journal of Applied Geophysics, 137, 104-117.

[2]. K. Tokimatsu, S. Tamura and K. Kojima,1992. Effects of Multiple Mode on Rayleigh Wave Dispersion Characteristics, Journal of Geotechnical Engineering, 118:152.

[3]. H. Okada 2003, TheMicrotremor Survey Method, Geophysical Monograph, No. 12, Society of Exploration Geophysicists, Tulsa.

[4]. H. Morikawa, S. Sawada, and J. Akamatsu, 2004, A MethodtoEstimatePhaseVelocities of RayleighWaves Using MicrotremorsSimultaneouslyObserved at TwoSites, Bulletin of theSeismologicalSociety of America, 94: 961-976.

[5]. C.B. Park, R.D. Miller, 2005. Seismiccharacterization of windturbinesites in Kansas bythe MASW method. Kansas GeologicalSurvey Open-file Report, 23.

[6]. C. Kıncal, 2004,Evaluation of geologicalunits in İzmir inner bay andit'svicinitybyusing GIS andremotesensingsystems in terms of engineeringgeology. Dokuz Eylül University, TheGraduate School of Natural andAppliedSciences, PhDThesis, İzmir. (in Turkish).

[7]. B. Uzel,H.Sözbilir, Ç. Özkaymak, 2012. Neotectonic evolution of an actively growing

[8]. superimposed basin in western Anatolia: the inner bay of Izmir, Turkey. Turk. J. Earth Sci. 21 (4), 439-471.

[9]. E. Pamuk, M. Akgün, Ö.C. Özdăg, \&Şahin, E. Şahin, 2016,Investigation of ShallowShearWaveVelocityStructure of East of Izmir Bay using 2D Multichannel Analysis of SurfaceWaves (MASW) method,BEUJournal of Science,5(2), 128-140 (in Turkish)

[10]. C.B. Park, R.D. Miller and J. Xia, 1999, Multichannelanalysis of SurfaceWaves, Geophysics, 64:800-808.

[11]. J.N. Louie, 2001, Faster, Better: Shear-WaveVelocityto 100 Meters Depth fromRefractionMicrotremorArrays, Bulletin of theSeismologicalSociety of America, 91: 347-364.

[12]. Nakamura Y (1989), "A methodfordynamiccharacteristicsestimation of sub-surfaceusingmicrotremor on thegroundsurface," Quarterly Report of Railway Technical ResearchInstitute, 30: 25-33.

[13]. Cirmik, A.,Ozdag, O. C., Dogru, F., Pamuk, E., Gonenc, T., Pamukcu, O., ... \& Arslan, A. T. (2016). TheSoilBehaviours of the GNSS Station. Earth, 5(5), 70-81.

[14]. Tunçel, A., Pamukçu, O., Gönenç, T., \& Akgün, M. (2016). Mikrotremor, Çok Kanallı Yüzey Dalgaları (ÇKYD) ve Mikrogravite Yöntemleri Kullanılarak Zemin Dinamik Özelliklerinin İrdelenmesi: Karşıyaka-İzmir Örneği ExaminingtheDynamicProperties of Soilby Using Microtremor, Multichannel Analysis of SurfaceWaves (MASW) andMicrogravity. Yerbilimleri Dergisi, 37(2).

[15]. Özdağ, Ö. C., Gönenç, T., \& Akgün, M. (2015). Dynamicamplificationfactorconcept of soillayers: a casestudy in İzmir (Western Anatolia). ArabianJournal of Geosciences, 8(11), 10093-10104. 